\title{
PROBABILISTIC FATIGUE DESIGN OF SHAFT FOR BENDING AND TORSION
}

\author{
Osakue, E. Edward ${ }^{1}$ \\ ${ }^{I}$ Texas Southern University, Houston, Texas, USA
}

\begin{abstract}
The ever increasing demand for better and reliable mechanical systems necessitates the explicit consideration of reliability in the modeling and design of these systems. Design for reliability (DFR) has been receiving a great deal of attention for several years and companies are deploying resources to the design for reliability process because of the need to satisfy customers and reduce warranty costs. In traditional or deterministic design, safety or design factors are usually subjectively assigned in product design so as to assure reliability. But this method of design does not provide a logical basis for addressing uncertainties, so the level of reliability cannot be assessed quantitatively.
\end{abstract}

This paper presents a probabilistic design approach for shafts under combined bending and torsional loads using the generalized Gerber fatigue failure rule. The design model parameters are considered as random variables characterized by mean values and coefficients of variation (covs). The coefficient of variation of the shaft design model is obtained by using first order Taylor series expansion for strength and stress in a stress-life fatigue design. A reliability factor is defined and related to the covs of design parameters and a failure probability. The design model assumes a lognormal probability density distribution for the parameters. This approach thus accounts for variability of design model parameters and provides quantitative assessment of product reliability. The approach is flow-charted for ease of application.

This study shows that deterministic engineering models can be transformed into probabilistic models that can predict the risk in a design situation. From the design examples considered, it is shown that the popular modified Goodman model (MGM) for stresslife fatigue design is slightly on the conservative side. The study indicates possible reduction in component size and hence savings in product cost can be obtained through probabilistic design. Probabilistic design seems to be the most practical approach in product design due to the inherent variability associated with service loads, material properties, geometrical attributes, and mathematical design models. The computations in the present model were done using Microsoft Excel. This demonstrates that probabilistic design can be simplified so that specialized software and skills may not be required, especially at the preliminary design phase. Very often, available probabilistic models are intensive in numerical computation, requiring custom software and skilled personnel. The model approach presented needs to be explored for other design applications, so as to the make probabilistic design a common practice.

Keywords: Fatigue, Failure, Reliability, Lognormal, Safety

\section{INTRODUCTION}

When a consumer buys a product, he or she expects it to function at least to the advertised performance standard(s) or specification(s) of the seller or manufacturer. In addition, there is the implied expectation of reliability and safety, for no customer would knowingly buy a product that is unreliable or worst still, unsafe! A good engineering design requires considering functionality, reliability, safety, manufacturability, operability, maintainability, and affordability. According to Hammer [1], a good engineer designs a product to preclude failures, accidents, injuries, and damages. Hence safety is at the heart of good engineering design practice. Designing safe products have been done for decades, or perhaps centuries, on the basis of a safety factor, a number greater than unity. A safety factor is subjectively assigned in practice so this approach does not provide a logical basis for addressing uncertainties or variability. With the safety factor method, the level of reliability cannot be assessed quantitatively [2], hence the safety margin in a design is practically unknown. Because of the difficulty of relating safety factor and product safety quantitatively, some prefer the term "design factor" to "safety factor" [3]. It is desirable to design components and products to expected levels of reliability (or failure probability), with the target level of reliability depending on specific consequences of failure. This would allow the development of risk-informed design methods and may result in potential savings [4].

A quantitative assessment of reliability, and hence safety, is possible through applications of probability and statistics. Therefore, statistical-probabilistic or reliability-based design has attracted great attention in the last few decades. For instance, Load and Resistance Factored Design (LRFD), a reliability-based method, has been developed and is being used in structural design. This approach is being studied for adoption in piping design. Reliability-based designs promote consistency, allow more efficient designs, and are more flexible and rational than working stress or safety factor 
methods because they provide consistent levels of safety over various types of structures and products [4]. Probabilistic design allows a quantification of risk that can help to avoid over- or under-design problems while ensuring that safety and quality levels are economically achieved [5]. Over design requires more resources than necessary and leads to costly products. Avoiding over-design helps to conserve product materials and reduce manufacturing resources, machining accuracy, quality control, etc. during processing. Under-designed products are prone to failures, making the products unsafe and unreliable. This increases the risks of product liability lawsuits, customer dissatisfaction, and even accidents [6]. Much research has been done in recent years on quantifying uncertainties in engineering systems and their effects on reliability.

In most real engineering problems, variation is inherent in material properties, loading conditions, geometric properties, simulation models, manufacturing precision, actual product usage, etc. [4, 7, 8]. Environmental conditions affect the reliability and service life of products. Temperature and humidity are probably two of such conditions that can significantly affect reliability [9]. But rain, hail, water quality, wind, snow, mud, sand, dust, etc. can also influence product reliability and service life [9]. Environmental conditions affect both service loads and material mechanical properties. It is not physically possible or financially feasible to eliminate variation of geometric design parameters. This is due to the fact that the reduction of variability is associated with higher costs either through better and more precise manufacturing methods and processes or increased efforts in quality. Accepting variability and limiting it is a more practical approach in design as it makes production more cost-effective and products more affordable [10]. In general, variability in stress-based design parameters can be grouped into two: strength variability and stress variability. Stress variability has two components of load variability and geometric variability. Generally, the variability of geometry is usually of a lesser degree compared to the variability in material properties or loads.

As mentioned earlier, a component or product failure probability should reflect the consequence of failure such as product damage or personnel injury $[11,12,13]$. According to Socie [14], failure probability of $10^{-6}$ to $10^{-9}$ for safety and $10^{-2}$ to $10^{-4}$ for economic damage may be considered acceptable. The aerospace industry specifies a failure probability of $10^{-5}$ in many cases, while the standard failure probability of rolling element bearings is $10^{-1}$ [11]. Ashby and Jones [15] says a failure probability of $10^{-1}$ may be acceptable for ceramic tool because it is easily replaced but one may aim at a value of $10^{-6}$ where failure may result in injury and probably $10^{-8}$ when one component failure could be fatal.

The use of probabilistic design methods requires some appropriate probability distribution [16]. The lognormal probability distribution has inherent properties that recommend it for machine and structural design applications
[17, 18]. Therefore, it is assumed in this study that the strengths of materials and service loads on equipment are distributed in the standard lognormal sense. Agrawal [19] observed that the cross-sectional area of structural members depended on the mean strength and standard deviation values of materials for a given load distribution [19]. This suggests that the coefficient of variation (cov), the ratio of standard deviation to mean value of model parameters, is appropriate for probabilistic design. The use of the cov is particularly desirable since it can be used to summarize the variability of a group of materials and equipment in an industrial sector $[20,21]$. As will be seen later, the cov fits in easily in the lognormal probability model.

The most problematic design situation is dynamic where machine and structural members are subjected to fatigue loading. About $80 \%$ to $90 \%$ of the failures of machine and structural members result from fatigue [22, 23]. Fatigue failure normally takes the form of brittle fracture at stresses well below the static strength of the materials [3, 24] which can be catastrophic sometimes. Fatigue failures are more likely when a tensile mean stress is present during a fatigue load cycle. Several models $[11,25]$ are available in literature addressing the influence of tensile mean stress on fatigue life. Among these are the Gerber (Germany, 1874), Goodman (England, 1899), and Soderberg (USA, 1930). According to Norton [25], the Gerber parabola fits experimental data on fatigue failure with reasonable accuracy, though considerable scatter exists. He noted that the Gerber parabola is a measure of the average behavior of ductile materials in fatigue resistance while the modified Goodman curve is that of minimum behavior. Shingley and Mischke [17], state that the Gerber parabola falls centrally on experimental data while the modified Goodman line does not. The modified Goodman criterion is in common but the Solderberg model is rarely used now because it is very conservative.

Because the traditional Gerber bending fatigue criterion captures fatigue failure data on an average performance basis; it can be associated with $50 \%$ reliability [18]. The model is therefore a strong candidate for probabilistic design if mean values of design parameters are used in it. Higher or lower reliabilities can be achieved through specific failure probability requirement and variability of design model parameters. Direct reliability-based design requires performing spectral analysis and extreme value analysis of loads. Serviceability and failure modes needs to be considered at different levels and appropriate loads, strength capacities, failure definitions need to be selected for each failure mode [4]. Now, several reliability-based design approaches have been proposed in the last five decades [2]. However, they are generally computationally intensive, involve numerical modeling, require specialized software, or require specialized skills. These seem to have restricted their use to complex and costly design applications. Mischke [26] stated that deterministic and familiar engineering computations are useful in stochastic problems if mean values are used. Therefore, deterministic models are suitable for probabilistic design if the variability of design model 
parameters is accounted for. Such an approach may simplify probabilistic design and alleviate issues of using complicated models and encourage the use of probabilistic design in conceptual and preliminary phases in a design project. Excel based design software can lead to reduction in design cost, and also speed up design as preliminary model sizes will be more accurate $[27,28]$.

\section{LOGNORMAL RELIABILITY MODEL}

The lognormal probability distribution function has inherent properties that make it an attractive choice for engineering design applications. For instance, the products and quotients of lognormal variates are lognormal and real powers of lognormal variates are also lognormal [17]. Now most design formulas are products and sums of design parameters: so they can be assumed to have lognormal distribution as a first approximation. Suppose in a strengthstress design model and in the physical domain, $S$ and $\sigma$ represent strength and stress, respectively. $S$ is the random variable for strength with mean value of $\mu_{s}$, standard deviation of $\varpi_{s}$, and cov of $\vartheta_{s} . \sigma$ is the random variable for stress with mean value of $\mu_{\sigma}$, standard deviation of $\varpi_{\sigma}$, and cov of $\vartheta_{\sigma}$. Then:

$$
\vartheta_{s}=\frac{\varpi_{s}}{\mu_{s}} \quad \vartheta_{\sigma}=\frac{\varpi_{\sigma}}{\mu_{\sigma}}
$$

A random variable $n$ with parameters $\mu_{\mathrm{n}}$ and $\vartheta_{\mathrm{n}}$ can be defined as the ratio of $S$ and $\sigma$. That is:

$$
\begin{aligned}
& n=\frac{S}{\sigma} \\
& \vartheta_{n}=\sqrt{\vartheta_{s}^{2}+\vartheta_{\sigma}^{2}}
\end{aligned}
$$

To preclude failure, $n$ must be greater than unity: that is, $\sigma<S$ If $\sigma \geq S$, then failure has occurred. Since $S$ and $\sigma$ have lognormal distributions, respectively, the quotient $n$, will be lognormal in distribution [17]. If $q$ is the random variable for the quotient $n$ in the lognormal domain, then:

$$
q=\ln (n)=\ln \left(\frac{S}{\sigma}\right)
$$

Based on the properties of lognormal distribution [29], if the parameters of $q$ are $\mu_{q}$ and $\varpi_{q}$, then:

$$
\begin{aligned}
& \mu_{q}=\ln \left(\mu_{n}\right)-0.5 \varpi_{q}^{2} \\
& \varpi_{q}=\sqrt{\ln \left\{1+\vartheta_{n}^{2}\right\}}=\sqrt{\ln \left\{1+\vartheta_{s}^{2}+\vartheta_{\sigma}^{2}\right\}}
\end{aligned}
$$

The probability density distribution of $q$ is normal and is depicted in Fig. 1a. Fig. 1b depicts the corresponding unit normal variate distribution. The failure probability associated with the unit normal variate is represented by the area under the normal distribution curve (shaded in Fig. 1b) and corresponds to the failure region in Fig. 1a (shaded).

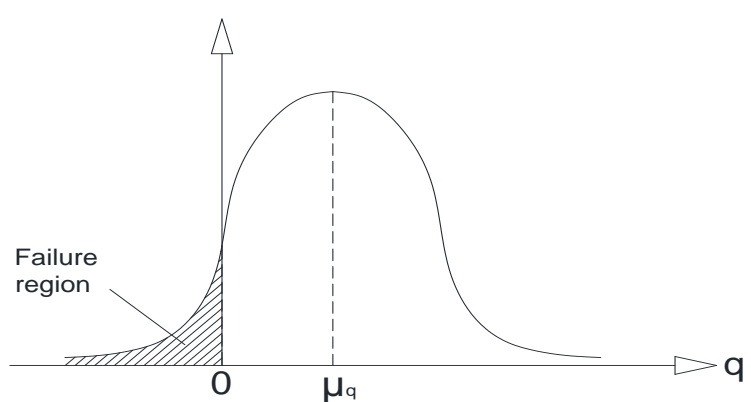

a). Normal distribution

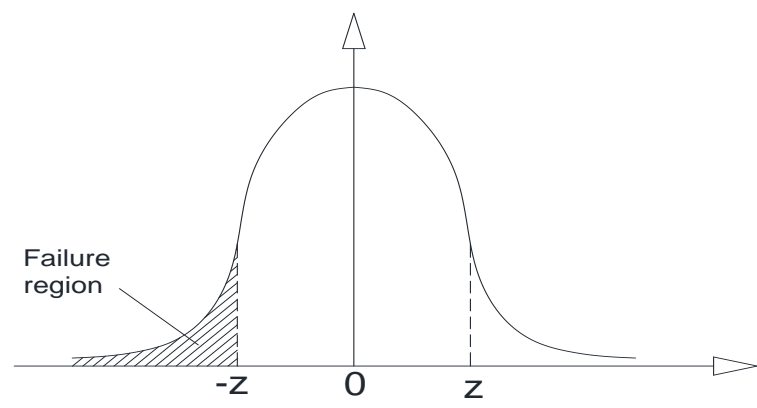

b) Unit normal distribution

Fig. 1: Random variable with normal distribution

The failure zone of a component or product is the region of $q \leq 0$ where $n \leq 1$. Referring to Fig. 1b, any normal variate $q$ on the left of $\mu_{q}$ in Fig. 1a corresponding to $-\mathrm{z}$ on the left of the origin in Fig. 1b can be obtained as:

$$
q=\mu_{q}-z \varpi_{q}
$$

Hence when $q=0$ :

$$
z=\frac{\mu_{q}}{\varpi_{q}}=\frac{\ln \left(\mu_{n}\right)-0.5 \ln \left\{1+\vartheta_{s}^{2}+\vartheta_{\sigma e f}^{2}\right\}}{\sqrt{\ln \left\{1+\vartheta_{s}^{2}+\vartheta_{\sigma e f}^{2}\right\}}}
$$

In a stress-strength based design, the reliability factor may be defined as:

$$
n_{z}=\frac{\text { Mean Stress Capabilty }}{\text { Mean Effective Stress }}=\frac{\mu_{S}}{\mu_{\sigma e f}}
$$


In fatigue design, $\mu_{S}=S_{f}$ or $\mu_{S}=S_{u t}$ in Eqn. 7, depending on the most likely failure mode [30]. For design application, it may be assumed that $\mu_{n}=n_{z}$ [17] in Equation (6). An engineering model can be deduced from Eqns. $4 \mathrm{a}$ and $4 \mathrm{~b}$ by introducing a slight modification on $\varpi_{q}$ expression by changing it to the value predicted by strength-stress overlap in probability density functions. This is given by $[17,18]$ :

$$
\varpi_{q}=\sqrt{\ln \left\{\left(1+\vartheta_{s}^{2}\right)\left(1+\vartheta_{\sigma e f}^{2}\right)\right\}}=\sqrt{\ln \left\{\left(1+\vartheta_{s}^{2}+\vartheta_{\sigma e f}^{2}+\vartheta_{s}^{2} \vartheta_{\sigma e f}^{2}\right)\right\}}
$$

Notice the product term $\left(\vartheta_{s}^{2} \vartheta_{\sigma e f}^{2}\right)$ in Eqn. 8 which is absent from Eqn. 4b. This implies that the value of $\varpi_{q}$ from Eqn. 8 will be slightly higher than that from Eqn. 4b. If Eqn. 8 is substituted in Eqn. 6; we have:

$$
z=\frac{\ln \left(n_{z}\right)-0.5 \ln \left\{\left(1+\vartheta_{s}^{2}\right)\left(1+\vartheta_{\sigma e f}^{2}\right)\right\}}{\left.\sqrt{\ln \left\{\left(1+\vartheta_{s}^{2}\right)\left(1+\vartheta_{\sigma e f}^{2}\right)\right.}\right\}}
$$

Eqn. 9 gives the unit normal variate $z$, based on the reliability factor and design model parameters variability. The substitution of Eqn. 8 for Eqn. 4b in Eqn. 6 to obtain Eqn. 9; slightly increases the denominator and simultaneously decreases the numerator. The overall effect of this is the reduction of the unit normal variate or $\mathrm{z}$ variable, so that the predicted reliability is conservative. This reliability is obtained as:

$$
R_{z}=1-\Phi(-z)=\Phi(z)
$$

Eqn. 10 gives the reliability for the unit normal variate $z$, with the value of $\Phi(-z)$ or $\Phi(z)$ read from an appropriate table. If a desired reliability or failure probability is specified then, $z$ is known and the necessary reliability factor $n_{z}$ for achieving this reliability level can be obtained. That is from Eqn. 9:

$$
n_{z}=\exp \left[\begin{array}{l}
z \sqrt{\ln \left\{\left(1+\vartheta_{s}^{2}\right)\left(1+\vartheta_{\sigma e f}^{2}\right)\right\}} \\
+0.5 \ln \left\{\left(1+\vartheta_{s}^{2}\right)\left(1+\vartheta_{\sigma e f}^{2}\right)\right\}
\end{array}\right]
$$

From Eqn. 11, if the variability of the significant factors in a design model can be estimated with reasonable accuracy, it is possible to design to a reliability target through a reliability factor. According to Wang, Kim and Kim [31], it is common to use the unit normal variate (Eqn. 9) for failure probability assessment because probability values (Eqn. 10) can change by several orders of magnitude over small changes in the unit normal variate. Since small changes in $\mathrm{z}$ could mean relatively higher changes in $R_{z}$; Eqn. 9 should yield conservative results for $R_{z}$ and perhaps allows its use in high reliability situations. An alternative to reading $R_{z}$ from Tables is discussed in the Appendix.

The mean and standard deviation or cov of design models must be evaluated in order to apply Eqns. 9, 10, and 11 . Suppose a function $\chi$, has the random variables $x_{1}, x_{2}, x_{3} \ldots \ldots x_{n}$ as independent variables. Then:

$$
\chi=f\left(x_{1}, x_{2}, x_{3} \ldots \ldots x_{n}\right)
$$

Based on Taylor series expected values for unskewed or lightly skewed distributions [17], a first order estimate of the mean and standard deviation of $\chi$ may be obtained respectively:

$$
\begin{aligned}
\mu_{\chi} & =f\left(\mu_{x 1}, \mu_{x 2}, \mu_{x 3} \ldots \ldots \mu_{x n}\right) \\
\varpi_{\chi} & =\sqrt{\sum_{i=1}^{n}\left(\frac{\partial \chi}{\partial x_{i}}\right)^{2} \varpi_{x_{i}}^{2}}
\end{aligned}
$$

The coefficient of variation is the ratio of standard deviation to the mean value:

$$
\vartheta_{\chi}=\frac{\varpi_{\chi}}{\mu_{\chi}}
$$

Eqn. 13a simply says that the mean value of a function is obtained by substituting mean values of its independent variables. Eqns. $13 \mathrm{~b}$ and 14 provide means of quickly obtaining the standard deviation and cov of the function using partial differentiation. The task in using the reliability model of Eqn. 9 is to develop expressions for $\vartheta_{S}$ and $\vartheta_{\sigma e f}$ for specific design models. Eqns.13a, 13b, and 14 are helpful in this task. The model application is not limited to stress-based design; it can be used for any serviceability criterion of interest such as lateral stability, transverse deflection, torsional rigidity, critical speed, etc. In this study, expressions for $\vartheta_{S}$ and $\vartheta_{\sigma e f}$ for Gerber bending fatigue failure rule for combined bending and torsional loads are developed.

\section{FATIGUE DESIGN}

A component or product is loaded in fatigue if it is subjected to some repeated force or bending moment loads. A load cycle is when the imposed load changes value from a minimum to a maximum and back to the minimum. Fatigue load cycles may be classified into two groups of finite-life and infinite-life load cycles as shown in Fig. 2, which is called the $S-N$ diagram. The vertical axis represents stress while the horizontal axis represents load cycles. In finite-life load cycle, a component or product fails at a limited number of load cycles and the life of the component is measured as the number of load cycles to failure. 


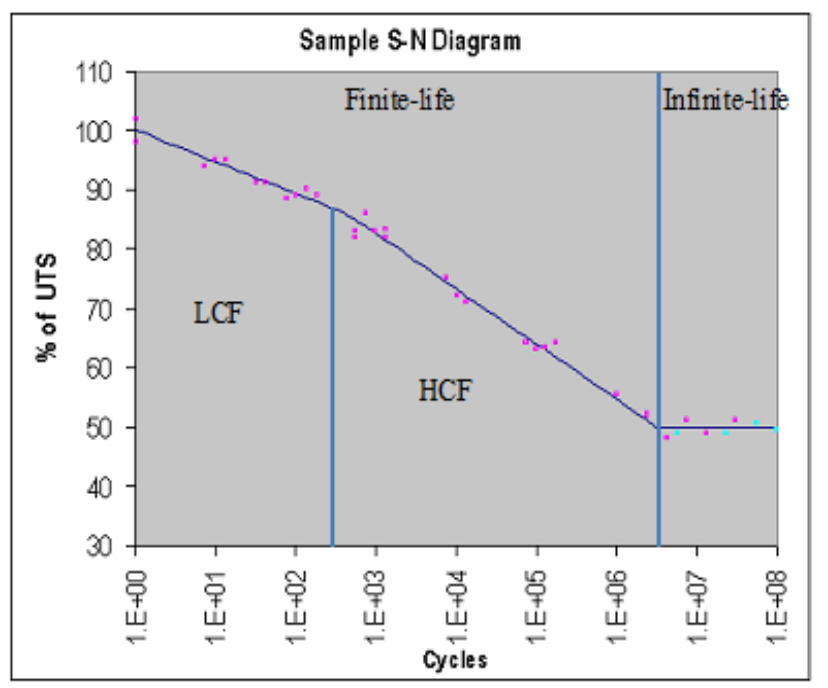

Fig. 2: $S$ - $N$ diagram [32, EPI Inc.]

Finite-life load cycle is divided into two regimes of lowcycle fatigue (LCF) and high-cycle fatigue (HCF). Lowcycle fatigue is when the load cycles are less than $10 \mathrm{k}$ but normally in the range of 100 to $10^{4}$ load cycles. In low-cycle fatigue, cyclic loads are relatively high, and significant levels of plastic strain are induced per load cycle, resulting in low numbers of load cycles before failure. High-cycle fatigue is when the number of load cycles is about $50 \times 10^{4}$ or more; but usually between $10^{3}$ to $10^{7}$ load cycles [11]. In high-cycle fatigue, strains are largely elastic, and cyclic loads are relatively low. In the finite-life regimes, the number of load cycles has some influence on the fatigue strength of materials, stress concentration factor, and notch sensitivity [17]. Infinite-life cycle is generally when a component or product is subjected to $10^{6}$ load cycles and above. In this regime, the material is able to sustain an unlimited number of load cycles at some low stress levels. Generally, the fatigue strength of materials may show little or no decrease with increasing fatigue load cycles in infinite-life fatigue. However, there is no universal agreement on the dividing line between finite-life and infinite-life regimes or between LCF and HCF as overlap exists from the classification of different authors [11, 25]. Ferrous alloys and titanium exhibit a rather well-defined fatigue limit, sometimes well before $10^{7}$ load cycles. Other nonferrous alloys do not exhibit a well-defined fatigue limit [11]. For materials without apparent finite-life, it is often taken to be $10^{8}$ to $5 \times 10^{8}$ load cycles. Some authors associate fatigue strength with the finite-life regimes and endurance strength or fatigue limit with the infinite-life regime.

Fatigue failure is generally a sudden, often catastrophic, separation of a part into two or more pieces due to fluctuating loads or deformations over a period of time. The loads or deformations that cause failure by fatigue are typically below static failure levels. When cyclic loads are tensile, fatigue cracks develop readily. This is aggravated by the presence of local stress raisers which may be due to poorly made welds, small holes (notches), rough or damage edges from manufacturing processes such as shearing, punching, and cutting [27]. According to Norton [25], three approaches are generally used in fatigue design. These are the stress-life $(S-N)$ approach, the strain-life $(\varepsilon-N)$ approach, and the linear elastic fracture mechanics $(L E F M)$ approach. The $S-N$ model is appropriate for the large class of rotating machinery (stationary or mobile), where shafts are commonly used, because the required load cycles are usually in the HCF range [25].

\subsection{Gerber Bending Fatigue Model}

The stress state in bending fatigue loading is appraised from the maximum and minimum stress values imposed on the structural or machine member during one load cycle. The damage from cyclic bending stress state is assessed on the basis of the mean and amplitude stresses. When a tensile mean stress is present during fatigue load cycle, the material can fail at alternating stress levels lower than the fatigue strength. Fig. 3 shows the Gerber bending fatigue design diagram. The vertical axis represents alternating stress amplitude while the horizontal axis represents mean stress. The limits of the amplitude stress and mean stress are the completely reversed bending fatigue strength and the ultimate tensile strength, respectively.

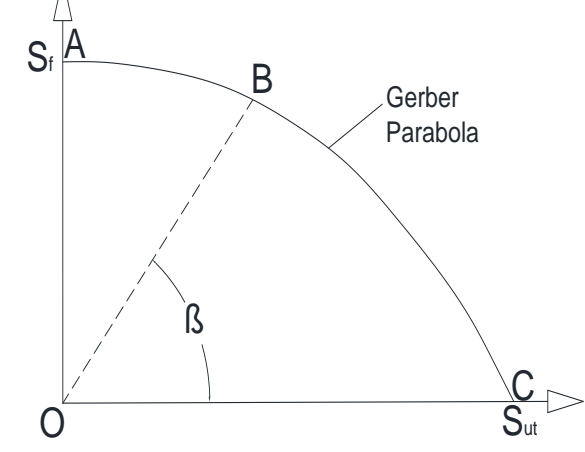

Fig. 3: Bending fatigue design diagram

In Fig. 3, the Gerber fatigue failure rule is represented by the Gerber curve ABC. The design space is divided by the line $\mathrm{OB}$ into two regions $\mathrm{OAB}$ called dynamic fatigue failure regime and $\mathrm{OBC}$ called static fatigue failure regime [30]. In region $\mathrm{OAB}$, material failure results from the predominant influence of the alternating stress while failure is due to the predominant influence of the mean stress in region OBC. Line OB (the transition line between the two regimes) makes angle $\beta$ with the horizontal line. The angle $\beta$ is a function of the service fatigue and tensile strengths of materials $[30,33]$ :

$$
\tan \beta=\eta_{t}=1.5 \psi_{s} \quad \psi_{s}=\frac{S_{f}}{S_{u t}}
$$

Please refer to the Nomenclature for the definition of symbols.

\subsection{Equivalent Bending Loads}


The original Gerber bending fatigue rule has to be modified in a stress state different from pure bending. This is achieved by using the vertical axis of Fig. 3 to represent equivalent alternating bending stress $\left(\sigma_{a e q}\right)$ and using the horizontal axis to represent equivalent mean bending stress ( $\left.\sigma_{\text {meq }}\right)$. When bending and torsional stresses are present, a realistic combination of normal (bending) stress and the shear (torsional) stresses must be done to obtain the equivalent bending stress. This can be done by using an appropriate failure criterion, depending on whether the material is ductile or brittle. Experimental evidence suggests that for ductile materials from which most shafts are often made, the distortion-energy theory of failure is appropriate $[11,25]$ for both static and dynamic load conditions. It is stated that stress concentration factors should not be applied to the mean loads for ductile materials but should be applied for brittle materials [11]. The equivalent alternating bending moment due to combined bending and torsion in dynamic fatigue regime is [30]:

$$
\begin{aligned}
& M_{a e q}=K_{o v} \sqrt{k_{\sigma}{ }^{2} M_{a}^{2}+0.75 k_{\tau}^{2} T_{a}^{2}} \\
& \sigma_{a e q}=\frac{M_{a e q}}{Z_{x}}
\end{aligned}
$$

Applying the rule of Eqn. 13b to Eqn. 16a and Eqn. 16b and simplifying, the cov of $\sigma_{a e q}$ for dynamic and static fatigue is:

$$
\begin{aligned}
& \vartheta_{a e q}^{2}=\vartheta_{z x}^{2}+\vartheta_{o v}^{2} \\
& +\frac{1}{\left(1+0.75 \beta_{a}^{2}\right)^{2}}\left[\begin{array}{l}
\vartheta_{k \sigma}^{2}+\vartheta_{b m a}^{2} \\
+0.75^{2} \beta_{a}^{4}\left(\vartheta_{k \tau}^{2}+\vartheta_{t m a}^{2}\right)
\end{array}\right] \\
& \beta_{a}=\frac{k_{\tau} T_{a}}{k_{\sigma} M_{a}}
\end{aligned}
$$

The equivalent mean bending moment due to combined bending and torsion in dynamic fatigue regime is [30]:

$$
\begin{aligned}
& M_{m e q}=K_{o v} \sqrt{M_{m}^{2}+0.75 T_{m}^{2}} \\
& \sigma_{m e q}=\frac{M_{m e q}}{Z_{x}}
\end{aligned}
$$

Applying the rule of Eqn $13 \mathrm{~b}$ to Eqns. $18 \mathrm{a}$ and $18 \mathrm{~b}$ and simplifying, the cov of $\sigma_{m e q}$ for dynamic fatigue is:

$$
\begin{aligned}
& \vartheta_{\text {meq }}^{2}=\vartheta_{z x}^{2}+\vartheta_{o v}^{2} \\
& +\frac{1}{\left(0.75+\beta_{m}^{2}\right)^{2}}\left[\begin{array}{l}
0.75^{2} \vartheta_{b m m}^{2} \\
+\beta_{m}^{4} \vartheta_{b m m}^{2}
\end{array}\right]
\end{aligned}
$$

$$
\beta_{m}=\frac{M_{m}}{T_{m}}
$$

Note that in Eqns. 17a and 19a:

$$
\begin{aligned}
& \vartheta_{b m a}^{2}=\vartheta_{b m m}^{2}=\vartheta_{b m}^{2} \\
& \vartheta_{t m a}^{2}=\vartheta_{t m m}^{2}=\vartheta_{t m}^{2} \\
& v_{k \tau}^{2}=v_{k \sigma}^{2}
\end{aligned}
$$

Expressions for $\vartheta_{b m}^{2}$ and $\vartheta_{t m}^{2}$ must be found based on the loading configuration of a design problem. For instance, when a point load is on a beam, bending moment is a function of the product of two parameters: force and length. Similarly, twisting moment is a function of the product of the same parameters. If a point load is superimposed on a distributed load, a different expression is required. The force components of the parameters $\vartheta_{b m}$ and $\vartheta_{t m}$ take care of additional increases in load due to local dynamics while $\vartheta_{o v}$ takes care of general overload.

Substituting Eqns. 20a, 20b and 20c in Eqns. 17a and 19a; these equations become, respectively:

$$
\begin{aligned}
& \vartheta_{a e q}^{2}=\vartheta_{z x}^{2}+\vartheta_{o v}^{2} \\
& +\frac{1}{\left(1+0.75 \beta_{a}^{2}\right)^{2}}\left[\begin{array}{l}
\vartheta_{k \sigma}^{2}+\vartheta_{b m}^{2} \\
+0.75^{2} \beta_{a}^{4}\left\{\vartheta_{k \sigma}^{2}+\vartheta_{t m}^{2}\right\}
\end{array}\right] \\
& \vartheta_{m e q}^{2}=\vartheta_{z x}^{2}+\vartheta_{o v}^{2} \\
& +\frac{1}{\left(0.75+\beta_{m}^{2}\right)^{2}}\left[\begin{array}{l}
0.75^{2} \vartheta_{t m}^{2} \\
+\beta_{m}^{4} \vartheta_{b m}^{2}
\end{array}\right]
\end{aligned}
$$

The equivalent alternating bending moment due to combined bending and torsion in static fatigue is the same as in dynamic fatigue. Since ductile materials behave like brittle materials under fatigue loads [25], it seems reasonable to apply stress concentration factors to mean load components in the static fatigue regime as is done with brittle materials $[11,25]$. Hence the equivalent mean bending moment due to combined bending and torsion in static fatigue is given by:

$$
M_{m e q}=K_{o v} \sqrt{k_{\sigma}{ }^{2} M_{m}{ }^{2}+0.75 k_{\tau}{ }^{2} T_{m}{ }^{2}}
$$

Eqn. 23 is similar to Eqn. 16a, and applying the rule Eqn. $13 \mathrm{~b}$ to Eqn. 23 and simplifying, the cov of the equivalent mean loads in static fatigue is: 


$$
\begin{aligned}
& \vartheta_{m e q}^{2}=\vartheta_{z x}^{2}+\vartheta_{o v}^{2} \\
& +\frac{1}{\left(0.75+K_{\sigma \tau}^{2} \beta_{m}^{2}\right)^{2}}\left[\begin{array}{l}
0.75^{2}\left(\vartheta_{k \sigma}^{2}+\vartheta_{t m}^{2}\right) \\
+K_{\sigma \tau}^{4} \beta_{m}^{4}\left\{\vartheta_{k \sigma}^{2}+\vartheta_{b m}^{2}\right\}
\end{array}\right] \\
& K_{\sigma \tau}=\frac{k_{\sigma}}{k_{\tau}}
\end{aligned}
$$

A design point is defined by the coordinates $\left(\sigma_{m e q}, \sigma_{\text {aeq }}\right)$ which has a load line that passes through the origin with a slope [30] given by

be inside the region $\mathrm{OBC}$ in Figure 3, and static fatigue failure applies.

\subsection{Dynamic Fatigue Failure Regime: $\eta \geq \eta_{t}$}

The design load capability in dynamic fatigue failure is determined by the service fatigue strength. If direct field measurements are made, $\vartheta_{f s}$ is obtained from test results. However, laboratory fatigue tests on small polished specimens of the material of interest $[11,17,25]$ can be used to estimate field or service fatigue strength by making use of adjustment or correction factors. In such a case, the service fatigue strength (Eqn. 26a) and coefficient of variation of the fatigue strength (Eqn. 26b) are estimated respectively as:

$$
\begin{aligned}
& S_{f}=\mathrm{C}_{\mathrm{sz}} \mathrm{C}_{\mathrm{sr}} \mathrm{C}_{\mathrm{tp}} S_{f}^{\prime} \\
& \vartheta_{S}=\vartheta_{f s}=\left[\vartheta_{f b}^{2}+\vartheta_{s z}^{2}+\vartheta_{s r}^{2}+\vartheta_{t p}^{2}\right]^{\frac{1}{2}}
\end{aligned}
$$

Alternatively, the basic fatigue strength may be estimated from the tensile strength and the service fatigue strength (Eqn. 27a) and coefficient of variation of the fatigue strength (Eqn. 27b) are estimated respectively as:

$$
\begin{aligned}
& S_{f}=\mathrm{C}_{\mathrm{sz}} \mathrm{C}_{\mathrm{sr}} \mathrm{C}_{\mathrm{tp}} \psi_{o} S_{u t}^{\prime} \\
& \vartheta_{S}=\vartheta_{f s}=\left[\vartheta_{s u}^{2}+\vartheta_{\psi o}^{2}+\vartheta_{s z}^{2}+\vartheta_{s r}^{2}+\vartheta_{t p}^{2}\right] \frac{1}{2}
\end{aligned}
$$

In design sizing and for the initial or first time estimate of shaft size, values of $k_{\sigma}, k_{\tau}$ and $n_{z}$ are required. The problem is that these factors depend on the shaft size which is yet unknown. For preliminary design, values of $k_{\sigma}$ and $k_{\tau}$, may be assumed [25] or set equal to $k_{\sigma}^{\prime}$ and $k_{\tau}^{\prime}$, respectively. But $k_{\sigma}^{\prime}$ is less than $k_{\sigma}$ and $k_{\tau}$ is less than $k_{\tau}^{\prime}$ due to the influence of notch sensitivity. For a first time estimate of size, a design factor $n_{o}$ can be used instead of $n_{z}$ (please refer to the Appendix) whereby $n_{o}$ is

$$
\eta=\frac{\sigma_{a e q}}{\sigma_{m e q}}=\frac{M_{a e q}}{M_{m e q}}
$$

If $\eta$ is equal to or greater than the load line transition factor $\eta_{t}$, then the design point will be inside the region OAB in Fig. 3 and dynamic fatigue failure applies. If $\eta$ is less than $\eta_{t} ;$ then the design point will approximated from the expression for $n_{z}$ (Eqn. 11). The $\vartheta_{n o}$ for estimating $n_{o}$ is obtained as:

$$
\vartheta_{n o}=\left[\vartheta_{m i s}^{2}+\vartheta_{a e q}^{2}+0.5\left(\vartheta_{u t}^{2}+\vartheta_{m e q}^{2}\right)\right]^{\frac{1}{2}}
$$

Eqn. 28a is obtained from Eqn. 32 by assuming $n_{m}=2$. Then Eqn. 11 is used to obtain $n_{o}$ as:

$$
n_{o}=\exp \left[\begin{array}{c}
z_{o} \sqrt{\ln \left\{\left(1+\vartheta_{s}^{2}\right)\left(1+\vartheta_{n o}^{2}\right)\right\}} \\
+0.5 \ln \left\{\left(1+\vartheta_{s}^{2}\right)\left(1+\vartheta_{n o}^{2}\right)\right\}
\end{array}\right]
$$

For a solid shaft, the initial size estimate is [30]:

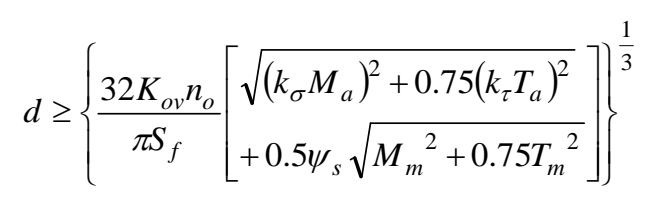

Eqn. 29 is of general application for solid circular shafts only. It can easily be modified for a hollow shaft. For the case of fully reversed bending and steady torque; $M_{m}=0$ and $T_{a}=0$ and:

$$
d \geq\left\{\frac{32 K_{o v} n_{o}}{\pi S_{f}}\left[k_{\sigma} M_{a}+0.25 \sqrt{3} \psi_{s} T_{m}\right]\right\}^{\frac{1}{3}}
$$

From [30], $\sigma_{e f}$ for generalized Gerber rule in dynamic fatigue is:

$$
\begin{gathered}
\sigma_{e f}=\frac{\sigma_{a e q}}{1-\frac{1}{n_{m}^{2}}} \\
n_{m}=\frac{S_{u t}}{\sigma_{m e q}}
\end{gathered}
$$


From [18], the cov of $\sigma_{e f}$ (Eqn. 31a) can be expressed as:

$$
\vartheta_{\sigma e f}=\left[\vartheta_{m i s}^{2}+\vartheta_{a e q}^{2}+\left(\frac{2}{n_{m}^{2}-1}\right)^{2}\left(\vartheta_{u t}^{2}+\vartheta_{m e q}^{2}\right)\right]^{\frac{1}{2}}
$$

The reliability factor is determined from Eqn. 7 as:

\subsection{Static Fatigue Failure Regime: $\eta<\eta_{t}$}

The design load capability in static fatigue failure is determined by the service tensile strength. If direct field measurements are made, $\vartheta_{u t}$ is obtained from test results. But, if the tensile data available are from laboratory tests on small polished specimens, then like the service fatigue strength, the service tensile strength (Eqn. 34a) and the cov of the tensile strength (Eqn. 34b) are estimated respectively as:

$$
\begin{aligned}
& S_{u t}=\mathrm{C}_{\mathrm{sz}} \mathrm{C}_{\mathrm{sr}} \mathrm{C}_{\mathrm{tp}} S_{u t}^{\prime} \\
& v_{S}=\vartheta_{u t}=\left[\vartheta_{s u}^{2}+\vartheta_{s z}^{2}+\vartheta_{s r}^{2}+\vartheta_{t p}^{2}\right] \frac{1}{2}
\end{aligned}
$$

As done previously, $n_{o}$ for static fatigue is approximated from the expression for $n_{z}$ (Eqn. 11) with $\vartheta_{n o}$ estimated as:

$$
\vartheta_{n o}=\left[\vartheta_{m i s}^{2}+\vartheta_{m e q}^{2}+0.25\left(\vartheta_{f s}^{2}+\vartheta_{a e q}^{2}\right)\right]^{\frac{1}{2}}
$$

Eqn. 35 is obtained from Eqn. 39 by assuming $n_{a}=2$. Then Eqn. $28 \mathrm{~b}$ is used to obtain $n_{o}$.

For a solid circular shaft:

$$
d \geq\left\{\frac{32 n_{o} K_{o v}}{\pi S_{u t}}\left[\begin{array}{l}
\left.\sqrt{\frac{2}{3 \psi_{s}}\left\{\left(k_{\sigma} M_{a}\right)^{2}+0.75\left(k_{\tau} T_{a}\right)^{2}\right.}\right) \\
+\sqrt{\left(k_{\sigma} M_{m}\right)^{2}+0.75\left(k_{\tau} T_{m}\right)^{2}}
\end{array}\right]\right\}^{\frac{1}{3}} 36
$$

If $M_{m}=0$ and $T_{a}=0$; for the case of fully reversed bending and steady torque, then

$$
d \geq\left\{\frac{32 n_{o} K_{o v}}{\pi S_{u t}}\left[\frac{2 k_{\sigma} M_{a}}{3 \psi_{s}}+\frac{k_{\tau} \sqrt{3}}{2} T_{m}\right]\right\}^{\frac{1}{3}}
$$

From [30, 33], $\sigma_{e f}$ for generalized Gerber bending fatigue rule in static fatigue is:

$$
n_{z}=\frac{S_{f}}{\sigma_{e f}}
$$

Results of Eqns. 32 and 33 are used in Eqn. 9 to evaluate the unit normal variate and the reliability is obtained by referring to appropriate table for $\Phi(z)$ from Eqn. 10 or using the expression for $R_{z}$ in the Appendix.

$$
\begin{aligned}
& \sigma_{e f}=\frac{\sigma_{m e q}}{\sqrt{1-\frac{1}{n_{a}}}} \\
& n_{a}=\frac{S_{f}}{\sigma_{a e q}}
\end{aligned}
$$

From [18], the cov of $\sigma_{e f}$ (Eqn. 38a) can be expressed as:

$$
\vartheta_{\sigma e f}=\left[\vartheta_{m i s}^{2}+\vartheta_{m e q}^{2}+\frac{1}{4}\left(\frac{1}{n_{a}-1}\right)^{2}\left(\vartheta_{f s}^{2}+\vartheta_{a e q}^{2}\right)\right]^{\frac{1}{2}}
$$

The reliability factor is determined from Eqn. 7 as:

$$
n_{z}=\frac{S_{u t}}{\sigma_{e f}}
$$

Results of Eqns. 39 and 40 are used in Eqn. 9 to evaluate the unit normal variate and the reliability is obtained by referring to appropriate table for $\Phi(z)$ from Eqn. 10 or using the expression for $R_{z}$ in the Appendix.

\section{DESIGN ANALYSIS}

Design analysis of a component generally involves iteration in two basic tasks: design sizing and design verification as depicted in Fig. 4.

\subsection{Design Sizing}

Design sizing involves the use of suitable serviceability criteria such as strength, transverse deflection, torsional deformation, buckling, etc. along with the type of loads and its configuration in deciding on an appropriate form and functional dimensions for a component with respect to a desired reliability level. Tolerances are determined and added to functional dimensions later. The form of a member is defined by its length and cross-sectional shape and dimensions over its length. In general, the cross-section may vary along the length of a member but this makes analysis more complicated and costly. Constant cross-sectional members are usually the first choice, especially during preliminary design but modifications often occur later in the design process. The length of a member is generally based on space limitation and may be estimated in a preliminary 
design layout diagram but can be refined later, perhaps from cross-section can be sized for an assumed shape based on fatigue strength or other serviceability criteria. The relevant serviceability in this paper is fatigue strength which should be related to bending moment and twisting moment loads and the geometry of a component. Bending stress can be expressed as a function of the bending moment and section rigidity or strength considerations. The modulus. Similarly, the torsional stress can be expressed as a function of the twisting moment and polar section modulus. Referring to Fig. 4, a brief explanation of the steps follows:

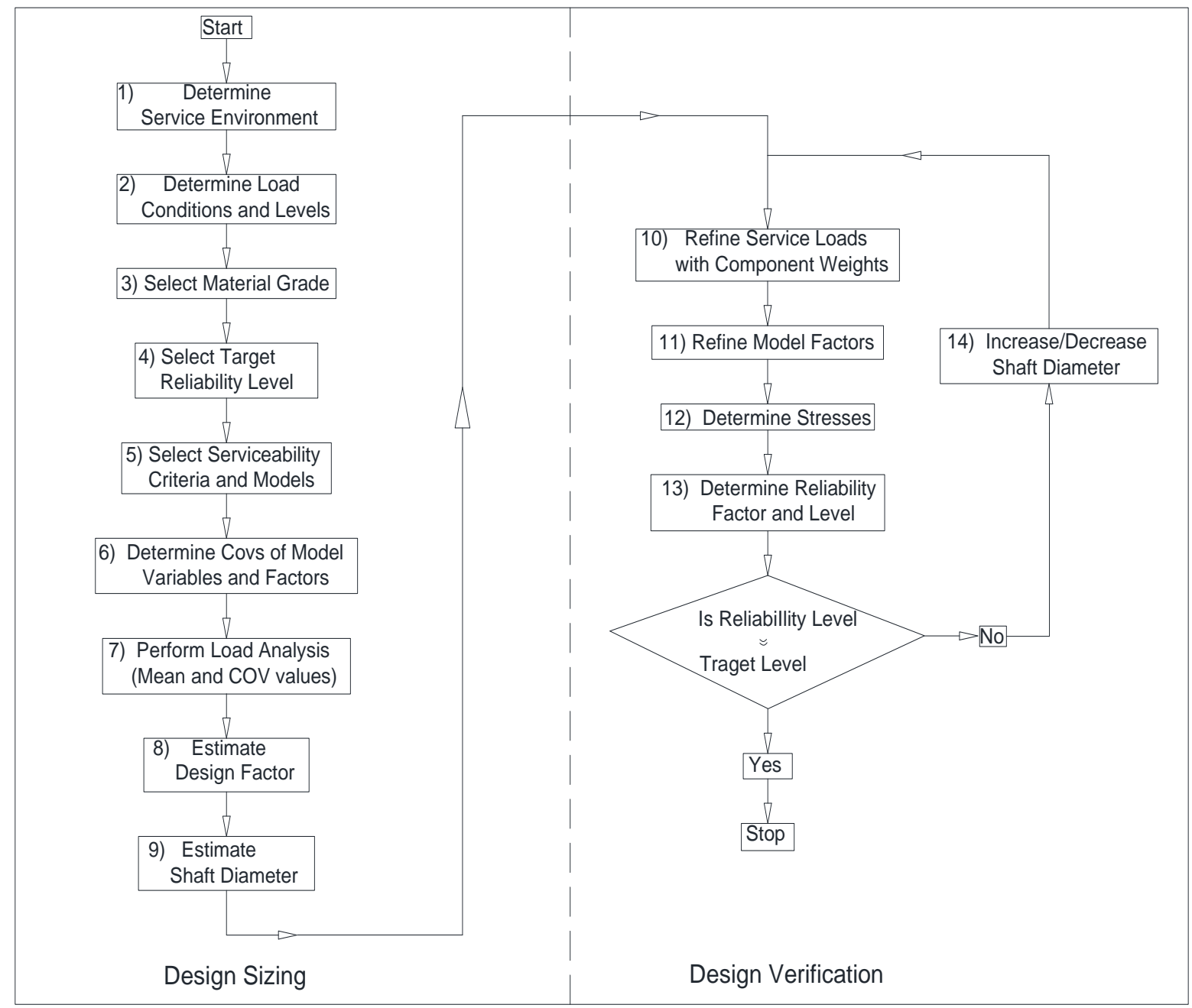

Fig. 4: Design Analysis

1. Analyze service environment. Will the equipment be used indoor or outdoor? Is the service temperature high or low? Is the humidity high or low? Is the atmosphere corrosive or normal? What are the range values of significant environment factors?

2. Analyze service load conditions. Is the load steady, dynamic, or transient? Is the dynamic load vibrational, fluctuating or impulsive? Are the main equipment users trained technicians or general public? What are the possible misuses or abuses? What are the maximum and minimum load values for transient and dynamic loads? What are the expected equipment life and load cycles? Generally, fatigue failure is associated with dynamic and or transient loads and steady loads give rise to static yield or fracture failure.

3. Based on conclusions of steps 1 and 2, select candidate material grade if fatigue failure is expected. Determine $S_{u t}^{\prime}, S_{u t}$ and $S_{u t}^{\prime}, S_{f}$.

4. Assess reliability requirements and determine minimum reliability level $\left(z_{o}\right)$.

5. From information in steps 1 and 2, conduct failure modes analysis and determine the most likely failure mode. This should be used for preliminary sizing, so select or develop applicable design formula(s) for the most likely failure mode. Checks for other modes should be made later.

6. Guided by steps 1 to 5 , research and estimate covs of design model variables and factors such as load, 
mechanical strength, stress concentration factors, etc.

7. Perform a load analysis, (better to develop shear force and bending moment diagrams, torque diagrams, etc.). Evaluate $F_{x}, F_{y}, F_{x y}, M_{\max }$, $M_{\min }, T_{\max }, T_{\min }, M_{m}, M_{a}, T_{m}, T_{a}$ (Eqns. 41, 42, and 43) at eachcritical section along the shaft. Assume $k_{\sigma}, k_{\tau}$. For example, set $k_{\sigma}=k_{\sigma}^{\prime}$, $k_{\tau}=k_{\sigma}^{\prime}$.

$$
\begin{gathered}
F_{x y}=\sqrt{F_{x}^{2}+F_{y}^{2}} \\
M_{m}=0.5\left(M_{\text {max }}+M_{\text {min }}\right) \\
M_{a}=0.5\left(M_{\text {max }}-M_{\text {min }}\right) \\
T_{m}=0.5\left(T_{\text {max }}+T_{\text {min }}\right) \\
T_{a}=0.5\left(T_{\text {max }}-T_{\text {min }}\right)
\end{gathered}
$$

Evaluate $\psi_{s}, \eta_{t}, \eta($ Eqns.15,25).

Determine $M_{\text {aeq }}, M_{\text {meq }}$ (Eqns. 16a, 18a, or 23).

\section{Estimate $n_{o}$}

8a: Dynamic fatigue (Eqns. 17b, 21, 22, 26b or 27b, $28 \mathrm{a}, 28 b)$.

8b: Static fatigue (Eqns. 19b, 21, 24, 34b, 35, 28b).

9. Estimate shaft size

9a: Dynamic fatigue (Eqns. 29 or 30)

9b: Static fatigue (Eqns. 36 or 37)

\subsection{Design Verification}

Design verification is done to ensure that the selected form and dimensions of a component or assembly meet design requirements. In probabilistic design, design verification is the assessment of the adequacy of a component size on the basis of a desired reliability target. A design is accepted as adequate if the evaluated expected reliability level is at least equal to a desired target. A factor of reliability greater than unity and a unit normal variate greater than zero are necessary for failure avoidance in probabilistic design. In deterministic design approaches, the safety factor or design factor is used for assessment. If the reliability factor of probabilistic design is interpreted as the design or safety factor of deterministic design, then deterministic design is contained in the probabilistic design model presented in this paper. Referring to Fig. 4:

10. Estimate weight of shaft and components carried by it. Refine $F_{x}, F_{y}, F_{x y}, M_{\max }, M_{\min }, T_{\max }, T_{\min }$, $M_{m}, M_{a}, T_{m}, T_{a}$ (Eqns. 41, 42, and 43) at each critical section along the shaft.

11. Determine $Z_{x}, k_{\sigma}, k_{\tau}$ and strength adjustment factors (Eqns. 26a, 27a, 34a) .

Refine $M_{a e q}, M_{m e q}$ (Eqns. 16a, 18a, or 23).

12. Determine $\sigma_{a e q}, \sigma_{m e q}$ (Eqns. $16 \mathrm{~b}, 18 \mathrm{~b}$ ).

Refine $\eta, \psi_{s}, \eta_{t}$ (Eqns. 15, 25). Determine $\sigma_{e f}$ (Eqn. 31 or 38 ).

13. Determine reliability factor, unit normal variate, and reliability level ( $n_{z}, z$, and $R_{z}$ ).

13a: Dynamic fatigue (Eqns. 32, 33, 9, 10)

13b: Static fatigue (Eqns. 39, 40, 9, 10)

14. If $z \approx z_{o}$, stop; otherwise increase/decrease shaft diameter and go to step 10 .

\section{APPLICATION EXAMPLES}

\subsection{Numerical Example 1}

Numerical Example 1 is a shaft design problem taken from reference [11, p. 348-352]. The problem statements have been paraphrased and data conversion to SI units was done by the author.

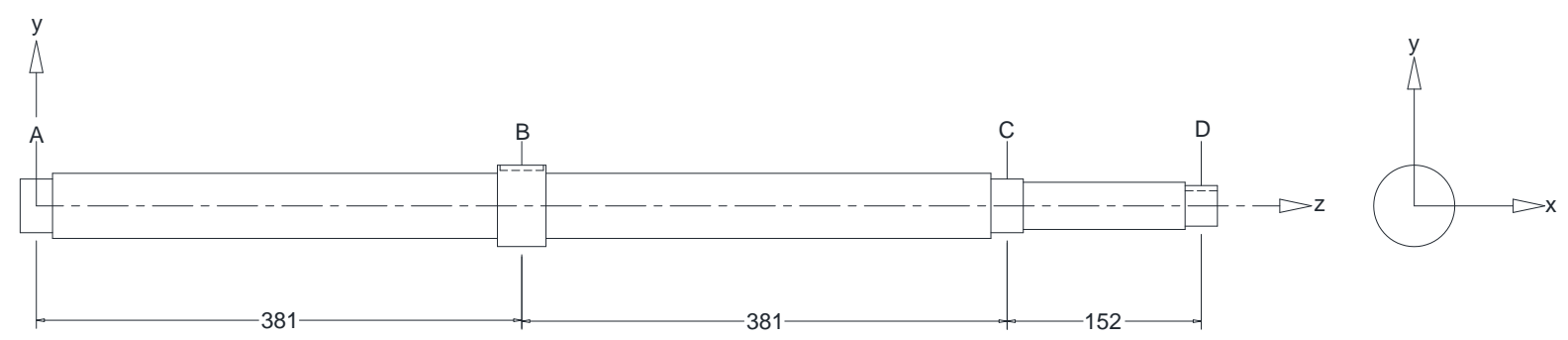

Fig. 5: Shaft sketch [After [11]] 
The proposed shaft in Fig. 5 has a gear at point $\mathrm{B}$ and a pinion at point $\mathrm{D}$. Points $\mathrm{A}$ and $\mathrm{C}$ are bearing seats. The load input on the shaft is at point B and the output is at point $D$. The proposed shaft material is hot-rolled AISI 1020 steel ( $S_{u t}=434 \mathrm{MPa}, \quad S_{f}=228 \mathrm{MPa}, e_{f}=36 \%$ ). Values of tensile and fatigue strengths were obtained from tests. Shoulder fillet radius for gear and bearing locations should be a minimum of $3.175 \mathrm{~mm}$. The results of the load analysis [11] are summarized in Table 1. Design the shaft with a design safety (reliability) factor of 2 .

Table 1: Load Analysis Summary for Example 1

\begin{tabular}{|l|l|l|l|l|l|}
\hline Point & $\begin{array}{l}\boldsymbol{F}_{\boldsymbol{x} \boldsymbol{y}} \\
(\mathbf{k N})\end{array}$ & $\begin{array}{l}\boldsymbol{M}_{\boldsymbol{a}} \\
(\mathbf{M N m})\end{array}$ & $\begin{array}{l}\boldsymbol{T}_{\boldsymbol{m}} \\
(\mathbf{M N m})\end{array}$ & $k_{\sigma}$ & $* k_{\tau}$ \\
\hline A & 15.7 & 0 & 0 & 1.6 & 1.3 \\
\hline B & 29.83 & 5.98 & 7.12 & 1.6 & 1.3 \\
\hline C & 154.92 & 18.19 & 7.12 & 1.6 & 1.3 \\
\hline D & 119.33 & 0 & 7.12 & 1.6 & 1.3 \\
\hline
\end{tabular}

To demonstrate the application of the approach presented in this work, both design sizing and design verification tasks will be performed on Fig. 5. To proceed with the tasks of design analysis, it is assumed that the overload factor is unity so that load values remain the same as in the original problem. This will allow reasonable comparison to be made between the original solutions and those from the approach here. It is also assumed that the shaft is ground at the critical sections of interest. For design analysis, the flow chart of Fig. 4 was used. Steps 1 to 4 were summarized in the original problem statement.

Table 2: Coefficients of Variation

\begin{tabular}{|l|l|l|l|}
\hline $\begin{array}{l}\text { Covs of Strength } \\
\text { Parameters }\end{array}$ & $\begin{array}{l}\text { Covs of } \\
\text { Parameters }\end{array}$ & Stress \\
\hline $\begin{array}{l}\text { Fatigue strength } \\
{[25]}\end{array}$ & 0.080 & $\begin{array}{l}\text { Overload } \\
\text { factor [11] }\end{array}$ & 0.050 \\
\hline $\begin{array}{l}\text { Tensile strength } \\
{[4,17]}\end{array}$ & 0.060 & Length [34] & 0.030 \\
\hline Size [18] & 0.001 & Depth [17] & 0.001 \\
\hline $\begin{array}{l}\text { Surface finish } \\
\text { ground ) [17] }\end{array}$ & 0.120 & $\begin{array}{l}\text { Stress } \\
\text { concentration } \\
\text { factor [17] }\end{array}$ & 0.110 \\
\hline \multicolumn{3}{|l|}{ Miscellaneous (Appendix) } & 0.085 \\
\hline
\end{tabular}

For step 6, the design formulas presented here were used, since fatigue failure mode (step 5) is expected. The research on model parameters variability (step 7) led to the data summarized in Table 2. The appropriate equations for design sizing (steps 7,8 and 9) were coded in Excel, Microsoft spreadsheet software. The maximum bending moments and other data in Table1 were provided as input data and the codes generated the output data. For design verification, steps 10 to 14 were performed with the equations coded in Excel. Variable step size was used during evaluation of reliability levels. It should be noted that separate equations were used for design analysis of points A and $\mathrm{D}$ since the shear forces at these points are large.

In the original solution, no strength adjustment factors were applied on the fatigue strength. In deterministic design, a fatigue strength correction factor is normally applied for reliability level above 50\% [25]. This would imply a reliability adjustment factor of unity or a reliability level of $50 \%$ for the fatigue strength for the original solution. Using the flow charted procedure in Fig. 4; sizing tasks were performed for $50 \%$ reliability level $(\mathrm{z}=0)$ and for reliability level of $99.87 \%(z=3)$. Tables $3 a$ and $3 b$ show the results of these tasks. The required reliability factor of 2 is satisfied in Table $3 \mathrm{~b}$, but not in Table $3 \mathrm{a}$. Therefore, the $50 \%$ reliability level solution is unacceptable. However, the design verification at $50 \%$ reliability level will still be carried out for completeness of model application.

Table 3a: Initial Sizing Solutions for $z=0$

\begin{tabular}{|l|l|l|l|}
\hline Point & $\boldsymbol{d}(\mathbf{m m})$ & $\boldsymbol{z}_{\boldsymbol{o}}$ & $\boldsymbol{n}_{\boldsymbol{o}}$ \\
\hline A & 14.50 & 0 & 1.035 \\
\hline B & 80.88 & 0 & 1.058 \\
\hline C & 113.23 & 0 & 1.058 \\
\hline D & 58.20 & 0 & 1.037 \\
\hline
\end{tabular}

Table 3b: Initial Sizing Solutions for $z=3$

\begin{tabular}{|l|l|l|l|}
\hline Point & $\boldsymbol{d}(\mathbf{m m})$ & $z_{\boldsymbol{o}}$ & $\boldsymbol{n}_{\boldsymbol{o}}$ \\
\hline A & 21.70 & 3 & 2.311 \\
\hline B & 102.61 & 3 & 2.161 \\
\hline C & 143.65 & 3 & 2.161 \\
\hline D & 78.10 & 3 & 2.323 \\
\hline
\end{tabular}

Table 4 shows the results of design verification for $50 \%$ reliability level, using the probabilistic model presented in this paper. It is clear that on the basis of the required safety factor of 2, these solutions are unacceptable. It is however, worth noting that the failure mode at point $\mathrm{D}$ is that of static fatigue while those for points $\mathrm{A}, \mathrm{B}$, and $\mathrm{C}$ is dynamic fatigue.

Table 4: Final Design Verification Solutions for $50 \%$ reliability

\begin{tabular}{|l|l|l|l|l|l|}
\hline Point & $\begin{array}{l}\boldsymbol{d} \\
(\mathbf{m m})\end{array}$ & $\begin{array}{l}\text { Failure } \\
\text { Mode }\end{array}$ & $\boldsymbol{n}_{z}$ & $\mathrm{z}$ & $\boldsymbol{R}_{z}$ \\
\hline A & 14.33 & Dynamic & 1.014 & 0.006 & 0.50 \\
\hline B & 78.37 & Dynamic & 1.024 & 0.001 & 0.50 \\
\hline C & 110.4 & Dynamic & 1.024 & 0 & 0.50 \\
\hline D & 56.85 & Static & 1.018 & 0.001 & 0.50 \\
\hline
\end{tabular}


Table 5 shows the results of design verification for 2.0 reliability factor with a maximum deviation of $0.8 \%$ at point A. Point B has the minimum reliability value of 0.99918 $(99.92 \%)$, that is at least " 3 nines". This is far from the $50 \%$ reliability implied by the fatigue strength value. Hence the traditional approach of assigning reliability level to fatigue strength alone is inadequate because other design parameters are not taken into consideration.

Table 5: Final Design Verification Solutions for Reliability Factor of 2

\begin{tabular}{|l|l|l|l|l|l|}
\hline Point & $\begin{array}{l}\boldsymbol{d} \\
(\mathbf{m m})\end{array}$ & $\begin{array}{l}\text { Failure } \\
\text { Mode }\end{array}$ & $\boldsymbol{n}_{z}$ & $\mathrm{z}$ & $R_{z}$ \\
\hline A & 20.2 & Dynamic & 2.016 & 4.210 & 0.999988 \\
\hline B & 96.0 & Dynamic & 2.014 & 3.142 & 0.99918 \\
\hline C & 138.0 & Dynamic & 2.015 & 3.150 & 0.9992 \\
\hline D & 69.3 & Static & 2.005 & 3.682 & 0.99989 \\
\hline
\end{tabular}

In Fig. 5, point A is only under transverse shear while point $\mathrm{D}$ is under direct shear and steady torsional loads. Points B and $\mathrm{C}$ are under steady torsion and alternating bending loads. Direct shear has been neglected at these points. Though the reliability factors at these points are practically the same, the reliability levels are different. This can only be explained on the basis of the loading conditions at the points. In parts, it shows, a reliability or safety factor in the traditional sense is not adequate is describing component or product reliability since a single reliability factor can lead to different reliability levels depending on the loading conditions at a point on a member. The modified Goodman rule, like other deterministic models, gives no reliability information.

Collins, Busby, and Staab [11] used the Modified Goodman model (MGM) for the preliminary sizing of the shaft of Fig. 5 and the second column of Table 6 , shows the shaft diameter solutions at the critical sections A, B, C, and D. Column 3 of Table 6 shows the reliability factor at the respective sections based on the reliability model developed previously. The reliability factors are all adequate being slightly above the required "safety factor" of 2. Column 4 is the corresponding unit normal variate to for the problem and column 5 gives the expected reliability level at each section. Section $C$ has the least reliability level of $99.96 \%$. Note that information in columns 4 and 5 are not available in the cited reference. They are estimated using the models developed in this paper. Though the safety or reliability factor at points A and $\mathrm{C}$ are practically the same, their reliability values of at least 5 "nines" and 3 "nines" are orders of magnitude apart. This reinforces the point made earlier that safety factor alone is insufficient in reliability assessment.

Table 6: Original Solutions for Design factor of 2

\begin{tabular}{|l|l|l|l|l|}
\hline Point & $\begin{array}{l}\boldsymbol{d} \\
(\mathbf{m m})\end{array}$ & $\boldsymbol{n}_{z}$ & $\mathrm{z}$ & $R_{z}$ \\
\hline A & 20.07 & 2.117 & 4.510 & 0.9999968 \\
\hline B & 99.82 & 2.277 & 3.713 & 0.99990 \\
\hline C & 139.95 & 2.104 & 3.347 & 0.99960 \\
\hline D & 71.12 & 2.185 & 4.156 & 0.999984 \\
\hline
\end{tabular}

\subsection{Numerical Example 2}

Numerical Example 2 (Fig. 6) is a shaft design problem taken from reference [35, p. 97-101] and the problem statements have been paraphrased. A drive shaft carries a spur gear between two bearings and an overhung pulley at one end. The shaft is to transmit $8 \mathrm{~kW}$ at $900 \mathrm{rpm}$. The spur gear has $20^{\circ}$ pressure angle and a pitch diameter of $192 \mathrm{~mm}$. The pulley has a diameter of $250 \mathrm{~mm}$ and the belt tension ratio can be taken as 2.5 . The gear and pulley are mounted on profiled keys on the shaft. The fillet radius at the gear and pulley shoulders is $3 \mathrm{~mm}$ and the masses of gear and pulley are $8 \mathrm{~kg}$ and $10 \mathrm{~kg}$, respectively. The shaft is to be manufactured from hot rolled alloy steel with $S_{u t}^{\prime}=1000 \mathrm{MPa}$ and a hardness of approximately $220 \mathrm{BHN}$.

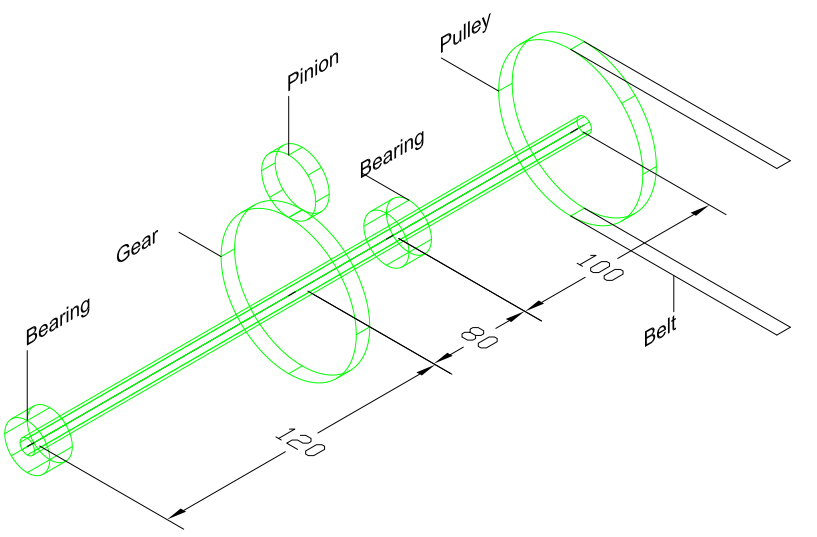

Fig. 6: (After Childs [35])

Using the ASME equation for the design of transmission shafting, determine the minimum nominal diameter for the shaft for a nominal reliability of $90 \%$ assuming a constant diameter shaft [35].

This second example problem is reliability based, unlike the previous one that was design factor based. Table 7 gives the summary of load analysis from the cited reference. Based on previous estimate of diameter; the estimated size factor is $C_{s z}=0.856$. The estimated surface roughness factor is $C_{s z}=0.405$ for hot-rolled steel material of $S_{u t}^{\prime}=1000 \mathrm{MPa}$ and the temperature factor $C_{s z}=1.0$. These factors give the estimated corrected $S_{u t}=347 \mathrm{MPa}$ and $S_{f}=175 \mathrm{MPa}$. Please refer to Eqns. 27 and 34. Notice that the surface roughness has a very strong influence on the strength values. A ground surface would more than double the strength values. The stress concentration factors are added to available data in the reference. The constant diameter shaft requirement in the problem statements means only the solution for the worst case load need be sought. This requirement will be relaxed in the solutions below.

Table 7: Load Analysis Summary for Numerical Example 2 


\begin{tabular}{|l|l|l|l|l|l|}
\hline Point & $\boldsymbol{F}_{x y}(\mathbf{N})$ & $\begin{array}{l}\boldsymbol{M}_{a} \\
(\mathbf{N m})\end{array}$ & $\boldsymbol{T}_{\boldsymbol{m}}(\mathbf{N m})$ & $k_{\sigma}$ & $k_{\tau}$ \\
\hline A & 452.4 & 0 & 0 & 1.60 & 1.30 \\
\hline B & 941.2 & 54.27 & 84.9 & 1.97 & 2.50 \\
\hline C & 1588.0 & 158.8 & 84.9 & 1.60 & 1.30 \\
\hline D & 2933.7 & 0 & 84.9 & 1.97 & 2.50 \\
\hline \multicolumn{7}{|l|}{$k_{\tau}$ and $k_{\sigma}$ are added by author } \\
\hline
\end{tabular}

Table 8 gives the initial or design sizing solutions at the critical sections of the shaft while Table 9 gives the final or design verification solutions. The diameter solution for the worst case load section (Point C) in [35] is $32 \mathrm{~mm}$.

Table 8: Initial Sizing Solutions for Numerical Example 2

\begin{tabular}{|l|l|l|l|l|}
\hline Point & $\begin{array}{l}\boldsymbol{d} \\
(\mathbf{m m})\end{array}$ & $\boldsymbol{n}_{\boldsymbol{o}}$ & $\mathrm{z}$ & $R_{z}(\boldsymbol{\%})$ \\
\hline $\mathrm{A}$ & 2.90 & 1.459 & 1.28 & 90 \\
\hline $\mathrm{B}$ & 21.85 & 1.502 & 1.28 & 90 \\
\hline $\mathrm{C}$ & 28.30 & 1.502 & 1.28 & 90 \\
\hline $\mathrm{D}$ & 19.8 & 1.463 & 1.28 & 90 \\
\hline
\end{tabular}

Table 9: Final Verification Solutions for Numerical Example 2

\begin{tabular}{|l|l|l|l|l|}
\hline Point & $\boldsymbol{d}(\mathbf{m m})$ & $n_{z}$ & $\mathrm{z}$ & $R_{z}(\%)$ \\
\hline A & 2.70 & 1.282 & 1.439 & 92.6 \\
\hline B & 21.00 & 1.408 & 1.279 & 90.6 \\
\hline C & 27.60 & 1.407 & 1.296 & 90.2 \\
\hline D & 18.50 & 1.307 & 1.370 & 91.54 \\
\hline
\end{tabular}

\section{DISCUSSION}

Tables 10a and 10b show a comparison between the initial or design sizing solutions and the final or design verification solutions. The initial solutions are always very slightly on the conservative. This is due to the use of the design factor which is an approximation of the reliability factor. Since the initial diameter sizes are slightly conservative, surprising changes in dimensions are not likely to arise during design verification.

The second thing to appreciate about the models in this paper is the closeness of the initial and final solutions. Most of the reduction value is lower that $7 \%$ with only one size being $11.3 \%$ smaller for Example 1. For this example, a trial value of $\mathrm{z}=3$ was used to obtain a reliability value close to 2. This may explain this difference. Since a reliability target was specified for the second example, no trial was necessary. Because of this closeness, iterations in the design verification task are fewer. This justifies one of the motivating factors for the development of the model which was to reduce design efforts.

It is appropriate at this point to compare solutions from the references and the new solutions. This is done in Tables 11a and $11 \mathrm{~b}$. For Example 1, the size reductions seem very modest, and for Example 2, the reduction is relatively substantial. These reductions could lead to potential savings in costs associated with size, manufacturing, inspection, assembly, and installation.

Table 10a: Initial and Final Shaft Diameter Sizes for Example 1

\begin{tabular}{|l|l|l|l|}
\hline Point & $\begin{array}{l}\text { Initial } \\
\boldsymbol{d}(\mathbf{m m})\end{array}$ & $\begin{array}{l}\text { Final } \\
\boldsymbol{d}(\mathbf{m m})\end{array}$ & $\begin{array}{l}\text { Reduction } \\
(\boldsymbol{\%})\end{array}$ \\
\hline A & 21.70 & 20.2 & 6.9 \\
\hline B & 102.61 & 96.0 & 6.4 \\
\hline C & 143.65 & 138.0 & 3.9 \\
\hline D & 78.10 & 69.3 & 11.3 \\
\hline
\end{tabular}

Table 10b: Initial and Final Shaft Diameter Sizes for Example 2

\begin{tabular}{|l|l|l|l|}
\hline Point & $\begin{array}{l}\text { Initial } \\
\boldsymbol{d}(\mathbf{m m})\end{array}$ & $\begin{array}{l}\text { Final } \\
\boldsymbol{d}(\mathbf{m m})\end{array}$ & $\begin{array}{l}\text { Reduction } \\
(\boldsymbol{\%})\end{array}$ \\
\hline A & 2.90 & 2.70 & 6.9 \\
\hline B & 21.85 & 21.00 & 3.9 \\
\hline C & 28.30 & 27.60 & 2.5 \\
\hline D & 19.8 & 18.50 & 6.6 \\
\hline
\end{tabular}

Table 11a: Previous and New Shaft Diameter Sizes for Example 1

\begin{tabular}{|l|l|l|l|}
\hline Point & $\begin{array}{l}\text { Original } \\
\boldsymbol{d}(\mathbf{m m})\end{array}$ & $\begin{array}{l}\text { New } \\
\boldsymbol{d}(\mathbf{m m})\end{array}$ & $\begin{array}{l}\text { Reduction } \\
(\boldsymbol{\%})\end{array}$ \\
\hline A & 20.07 & 20.2 & 2.4 \\
\hline B & 99.82 & 96.0 & 3.8 \\
\hline C & 139.95 & 138.0 & 1.4 \\
\hline D & 71.12 & 69.3 & 2.6 \\
\hline
\end{tabular}

Table 11b: Previous and New Shaft Diameter Sizes for Example 2

\begin{tabular}{|l|l|l|l|}
\hline Point & $\begin{array}{l}\text { Original } \\
\boldsymbol{d}(\mathbf{m m})\end{array}$ & $\begin{array}{l}\text { New } \\
\boldsymbol{d}(\mathbf{m m})\end{array}$ & $\begin{array}{l}\text { Reduction } \\
(\boldsymbol{\%})\end{array}$ \\
\hline A & - & 2.70 & - \\
\hline B & - & 21.00 & - \\
\hline C & 32 & 27.60 & 13.8 \\
\hline D & - & 18.50 & - \\
\hline
\end{tabular}


For example, the bearing bore size based on the original solution is $35 \mathrm{~mm}$ for Example 2. But the bearing bore size based on the new solution is $30 \mathrm{~mm}$. A ball bearing with 35 $\mathrm{mm}$ bore size will require larger bearing housing, retaining ring, etc. than one with a $30 \mathrm{~mm}$ bore size. Hence if the sizes estimated are satisfactory after considering other serviceability criteria such as lateral deflection, torsional deformation, critical whirling speed, and stability or buckling resistance; substantial cost savings could result. This is because smaller sizes are often easier and faster to make and transport. The machining cost of components is also influenced by size. To some extent, the inspection, assembly, and maintenance costs are all influenced by size. If the equipment is needed in large quantity, then thousands, if not millions of dollars, could be saved due to smaller sizes.

Both the Modified Goodman (MGM) and ASME models allow reliability specification to be applied to the fatigue strength. This study shows that the nominal reliability specification may be quite different from the actual expected value. The fact is that other design parameters are subject to variations just as the fatigue strength. Hence the totality of these parameter variations should be considered. Now a nominal reliability of $50 \%$ seems to apply to Example 1 based on the MGM. However, the estimated expected reliability is at least $99.96 \%$. Also the nominal reliability for Example 2 is $90 \%$ based on the ASME model, but the estimated expected reliability is at least $99.92 \%$. The gross under estimation of reliability in these cases may be due more to the MGM and ASME models' conservative positions relative to fatigue failure experimental data. MGM is not close to average behavior of materials as the Gerber fatigue model is [25]. The ASME model may not also be close to the average behavior of materials in fatigue failure. Because the new model can provide explicit reliability values, it is an improvement on the MGM and ASME models.

\section{CONCLUSIONS}

A reliability model has been developed for probabilistic design. The model is applied to the design of a shaft loaded in combined bending and torsion. In the reliability model, a reliability factor is determined based on a target reliability level, strength coefficient of variation, and stress coefficient of variation. The stress coefficient of variations is estimated using a first-order Taylor series expansion. The Gerber bending fatigue rule was extended for applications in combined bending and torsion using the concept of equivalent bending loads. The shaft design method uses the reliability factor in standard deterministic design formulas. For initial design sizing, a design factor is approximated from the reliability factor by simplifying the stress coefficient of variation. For design verification, the expected stresses are evaluated and used in the Gerber fatigue failure equation to assess the reliability of the design. This design approach simplifies the computational requirements of probabilistic design and can help make probabilistic design a common practice in machine design.
The examples considered show that size reductions are possible with probabilistic design. Also explicit estimates of reliability levels are possible. It was demonstrated that nominal reliability level that specified only on the material strength can be quite different from expected actual values with some fatigue design models. Probabilistic design provides quantitative risk assessment and permits reduction in component sizes compared to deterministic approaches. It avoids over- or under-design problems, leads to more economical products, and help conserves scares and nonrenewable materials.

In reliability-based design, the reliability factor and reliability level cannot be independently specified. The target reliability level should be explicitly specified so that the appropriate reliability factor can be determined. The modified Goodman rule like other deterministic models; gives no reliability information and can be conservative. From Tables 6 and 9, it seems appropriate to conclude that the approach outlined in this paper gives reasonable results. It has the additional advantage of providing specific reliability level information on a design. Also it demonstrates that probabilistic design can be done with cheap non-specialized software such as Microsoft Excel. It is recommended that new equipment should be designed for minimum size and weight while assuring reliability and customer satisfaction by using reliability-based design approaches.

\section{ACKNOWLEDGEMENTS}

This study was supported in parts with funds from COST Faculty Development Fund of Texas Southern University, Houston, Texas.

\section{REFERENCES}

[1]. Hammer, W. (1972), Handbook of System and Product Safety, Prentice-Hall, Englewood Cliffs, N.J.

[2]. Zhang, Y. M., He, X D, Liu, Q L, and wen, B C, (2005), An Approach of Robust Reliability Design for Mechanical Components, Proc. IMechE, Vol. 219, part E. pg. 275 - 283. Doi: 0.1243/095440805X8566. (http://www.paper.edu.cn).

[3]. Mott, R, L., (2008), Applied Strength of Materials, $5^{\text {th }}$ ed., Pearson Prentice Hall, Upper Saddle River, N.J.

[4]. ASME, (2007), Development of Reliability-Based Load and Resistance Factor Design (LRFD) Methods for Piping, ASME, New York, NY, pp. 2, 8.

[5]. Cullimore, B. and Tsuyuki, G., ( 2002), Reliability Engineering and Robust Design: New Methods for Thermal/Fluid Engineering, Proc., of $11^{\text {th }}$ Thermal and Fluid Verification

[6]. Kalpakjian, S. and Schmid, S. R., (2001) Manufacturing Engineering and Technology, 4th Ed. Pearson Prentice Hall, Upper Saddle River, N.J.

[7]. Koch, P., (2002). Probabilistic Design: Optimization for Six-Sigma Quality, $43^{\text {rd }}$ AIAA/ASME/ASCE/AHS/ASC Conference. April 22 - 25. Denver, Colorado.

[8]. Shigley, J. E. \& Mitchell, L. D., (1983), "Mechanical Engineering Design”, McGraw-Hill, New York, 
[9]. Avoiding Common Mistakes and Misapplications in Design for Reliability (DFR), http://www.reliasoft.com/newsletter/v12i1/systhesis.htm.

[10]. Understanding Probabilistic Design, http://www.kxcad.net/ansys/ANSYS/ansyshelp/Hlp_G_AD VPDS1.html, Accessed 10-12-12.

[11]. Collins, A. J., Busby, H., and Staab, G., (2010), Mechanical Design of Machine Elements, John Wiley \& Sons, New Jerey.

[12]. Juvinall, R. C. (1983), Fundamentals of Machine Components Design, Wiley, New York, pp. $200-23$

[13]. Shigley, J. E. and Mischke, C. R. (Chief Editors), (1996), Standard Handbook of Machine Design, McGrawHill, New York. p. 13.24 - 13.25

[14]. Socie, D, (2005), Probabilistic Aspects of Fatigue, http://www.efatigue.com/training/probabilistic_fatigue.pdf

[15]. Ashby, F. M., \& Jones, D. H. R. (1986). Engineering

Materials 2: An Introduction to Microstructure, Processing and Design. Oxford, Pergamon.

[16]. Johnson, C. R. (1980), Optimum Design of Mechanical Elements, Wiley, New York.

[17]. Shigley, J. E and Mischke, C. R. (Chief Editors), (1996), Standard Handbook of Machine Design, McGrawHill, New York.

[18]. Osakue, E. E. (2013), Probabilistic Design with Gerber Fatigue Model, Mechanical Engineering Research, Vol. 1, pp. 99 -117, doi:10.5539/mer.v3n1p99.

[19]. Agrawal, Avinash Chandra, (1971), On the Probabilistic Design of Critical Engineering Components, http://circle.ubc.ca/handle/2429/34397.

[20]. Pandit, S. M. and Shiekh, A. K., (1980), "Reliability and Optimal Replacement via Coefficient of Variation, Journal of Machine Design, Vol. 102, 761 -768.

[21]. Roshetov, D., Ivanov, A. and Fadeev, V. (1990), Reliability of Machines, MIR, Moscow, Chap. 4.

[22]. Kravchenko, P. YE., (1964), Fatigue Resistance, Pergamon, New York.

[23]. Sachs, N., (1999), Root Cause Failure VerificationInterpretation of Fatigue Failures, Reliability Magazine, August.

[24]. Hidgon, A., Ohseen, E. H., Stiles, W. B., and Weesa, J. A., (1967), Mechanics of Materials, $2^{\text {nd }}$. Ed. Wiley, New York, Chap. 10.

[25]. Norton, R. L. (2000), Machine Design: An Integrated Approach, Prentice-Hall, Upper Saddle River, New Jersey.

[26]. Mischke, C. R., (1996), Statistical Considerations, In Standard Handbook of Machine Design, Shigley, J. E. and Mischke, C. R. (Chief Editors), McGraw-Hill, New York. [27]. Johnston, B. G., Lin, F. J., and Galambos, T. V., (1986), Basic Steel design, $3^{\text {rd }}$ ed., Prentice-Hall, Upper Saddle River, New Jersey, p. 267.

[28]. Bausbacher, E. And Hunt, R. (1993), Process Plant Layout and Piping Design, Prentice Hall, p. 271.

[29]. Lognormal Distribution, Engineering Statistics Handbook,

http://itl.nist.gov/div898/handbook/eda/section3/eda3669.ht m, Accessed April. 12, 2014

[30]. Osakue, E. E., Anetor, L. and Odetunde, C., (2012), A Generalized Linearized Gerber Fatigue Model, Machine Design, Vol. 4, ISSN 1821-1259, p. 1-10.
[31]. Wang, H., Kim, N. H., and Kim, Y., (2006), Safety Envelope for Load Tolerance and its Application to Fatigue Reliability, Journal of Mechanical Design, Vol. 128, pp. 919 $-927$.

[32]. EPI Inc., (2008), "Metal Fatigue-Why Metal Parts Fail from Repeatedly Applied Loads".http://www.epieng.com/mechanical_engineering_basics/fatigue_in_metals. htm. Accessed 12-16-13.

[33]. Osakue, E. E. (2012), A Linearized Gerber Fatigue Model, International Journal of Modern Engineering, Vol. 12, No 1, pp. 64 - 72.

[34]. Matthews, C. (2005). ASME Engineer's Data Book, $2^{\text {nd }}$ ed. ASME Press, p. 63 \& 87.

[35]. Childs, P. R. N. (2004), Mechanical Design, $2^{\text {nd }}$. ed., Elsevier, Asterdam, p. 97-101.

\section{NOMENCLATURE}

$\psi_{s}=$ service fatigue ratio

$\psi_{o}=$ basic fatigue ratio

$\eta=$ load line slope factor

$\eta_{t}=$ load line slope transition factor

$\beta=$ load line transition angle

$\beta_{a}=$ alternating bending load factor

$\beta_{m}=$ mean bending load factor

$\sigma_{m}=$ mean bending service stress

$\sigma_{a}=$ alternating bending service stress

$\tau_{m}=$ mean shear service stress

$\tau_{a}=$ alternating shear service stress

$\sigma_{a e q}=$ equivalent alternating bending service stress

$\sigma_{\text {meq }}=$ equivalent mean bending stress

$\sigma_{e f}=$ effective bending stress

$\tau_{e f}=$ effective shear stress

$k_{\sigma}=$ service bending stress concentration factor

$k_{\sigma}^{\prime}=$ theoretical bending stress concentration factor

$k_{\tau}=$ service shear stress concentration factor

$k_{\tau}^{\prime}=$ theoretical shear stress concentration factor

$Z_{x}=$ section modulus of member about $\mathrm{x}$-axis

$Z_{y}=$ section modulus of member about $y$-axis

$Z_{p}=$ polar section modulus of member

$n_{m}=$ mean stress ratio relative to tensile strength

$n_{a}=$ ratio of effective alternative stress to fatigue strength

$F_{x}=$ shear force load in x-direction

$F_{y}=$ shear force load in y-direction

$F_{x y}=$ resultant shear force load in radial direction

$T_{\min }=$ minimum twisting moment value

$T_{\max }=$ maximum twisting moment value 
$T_{m}=$ twisting moment mean value

$T_{a}=$ twisting moment alternative value

$M_{\text {min }}=$ minimum bending moment value

$M_{\text {max }}=$ maximum bending moment value

$M_{m}=$ bending moment mean value

$M_{a}=$ bending moment alternative value

$M_{\text {meq }}=$ equivalent bending moment mean value

$M_{\text {aeq }}=$ equivalent bending moment alternative value

$d=$ shaft solid diameter

$\beta_{z}=$ minor-to-major ratio of section moduli

$e_{f}=$ fracture engineering strain on $50 \mathrm{~mm}$ gauge length

$S_{f}^{\prime}=$ laboratory test fatigue strength

$S_{f}=$ service or corrected fatigue strength

$S_{u t}^{\prime}=$ laboratory test ultimate tensile

$S_{u t}=$ service or corrected ultimate tensile strength

$C_{s z}=$ size adjustment factor

$C_{s r}=$ surface roughness adjustment factor

$C_{t p}=$ temperature adjustment factor

$\vartheta_{S}=$ coefficient of variation of strength

$\vartheta_{\sigma e f}=$ coefficient of variation of effective normal stress,

$\sigma_{e f}$

$\vartheta_{\psi o}=$ coefficient of variation of basic fatigue ratio

$\vartheta_{n o}=$ coefficient of variation of design factor

$\vartheta_{o v}=$ general overload coefficient of variation

$\vartheta_{b m}=$ local coefficient of variation of mean/alternating bending moment

$\vartheta_{t m}=$ local coefficient of variation of mean/alternating twisting moment,

$\vartheta_{z x}=$ coefficient of variation of section modulus

$\vartheta_{b m m}=$ local coefficient of variation of mean bending moment

$\vartheta_{b m a}=$ local coefficient of variation of alternating bending moment

$\vartheta_{t m m}=$ local coefficient of variation of mean twisting moment

$\vartheta_{t m a}=$ local coefficient of variation of alternating twisting moment

$\vartheta_{k}=$ coefficient of variation of service stress concentration factor

$\vartheta_{d l}=$ coefficient of variation of the load due to local dynamics

$\vartheta_{l}=$ coefficient of variation of member length $\vartheta_{h}=$ coefficient of variation of cross-section depth h (same for width $b$ or diameter $d$ )

$\vartheta_{\text {mis }}=$ miscellaneous coefficient of variation

$\vartheta_{u t}=$ service tensile strength coefficient of variation

$\vartheta_{f_{s}}=$ service fatigue strength coefficient of variation

$\vartheta_{f b}=$ laboratory fatigue strength coefficient of variation

$\vartheta_{s z}=$ size coefficient of variation

$\vartheta_{s r}=$ surface roughness coefficient of variation

$\vartheta_{t p}=$ temperature coefficient of variation

$\vartheta_{s u}=$ laboratory tensile strength coefficient of variation

$\chi=$ a primary dependent random variable

$x_{i}=\mathrm{i}^{\text {th }}$ independent random variable

$y=$ a secondary dependent random variable

$f()=$ function of independent variables

$S=$ strength random variable

$\sigma=$ stress random variable

$q=$ failure stress lognormal random variable

$\mu=$ mean value variable

$\mu_{S}=$ strength variable mean value

$\mu_{\sigma}=$ stress variable mean value

$\mu_{q}=$ mean lognormal failure stress variable

$\varpi_{S}=$ strength standard deviation

$\varpi_{\sigma}=$ stress standard deviation

$\varpi_{q}=$ lognormal failure stress standard

deviation

$z=$ unit normal variate

$z_{o}=$ target unit normal variate

$n_{z}=$ design reliability factor at $z$

$n_{o}=$ design factor

$R_{z}=$ reliability at $z$

$\Phi=$ cumulative probability density function

$\Phi(z)=$ normalized normal reliability function

$\Phi(-z)=$ normalized normal un-reliability function

$r_{f}=$ fillet radius

$K=$ generic factor

$K_{o v}=$ general overload factor

$K_{\sigma \tau}=$ ratio of normal to shear stress

concentration factors

$a, b, c=$ functional indices

A, B, C, D: points on a shaft

\section{APPENDIX}

This Appendix discusses design factor, miscellaneous variability and the estimate of reliability using the unit normal variate. 


\section{A1.1 Design Factor}

Design involve uncertainties due to variability in loading conditions, material properties, geometric properties, accuracy of analytical models, fabrication and installation precision, examination and inspection results, and in actual usage [4]. Design uncertainties have been traditionally handled through the use of safety or design factors. In strength-stress based design, the design factor may be defined as:

$$
n_{o}=\frac{\text { Strength }}{\text { Design or Allowable Stress }}
$$

The design factor is experiential and includes load and material strength uncertainty [17]. The value of the design factor is usually chosen by the designer based on experience and judgment [3, Chap. 3]. In some situations, codes, standards or company's policy may specify design factors or design stresses. In other situations, the designer must carefully consider the nature and manner of loading, the environment, material type (ductile or brittle), possible failure and hazard (s), misuse or abuse, quality control, market segment, accuracy of stress models, and cost. He or she must make conservative estimates that will ensure that the design is safe for all possible variations. An unduly high design factor leads to over-design resulting in over-sized components while an unduly low design factor leads to under-design with higher risk of failure. It is wasteful to purposely over-design and unwise to purposely underdesign.

In the approach presented in this paper, a design factor is estimated using a simplified version of the equation for the reliability factor for the purpose of initial sizing. This approach ensures that a reasonable design factor based on conditions similar but not identical to actual service conditions is used in initial design. The design factor in this case is solely a function of the reliability variable, the variability of material strength and the variability of stress model variables and factors. For dynamic fatigue design sizing, the factor $n_{m}$ is assigned a value of 2 . This simplifies Eqn. 32 approximately to:

$\vartheta_{n o}=\left[\vartheta_{m i s}^{2}+\vartheta_{a e q}^{2}+0.5\left(\vartheta_{u t}^{2}+\vartheta_{m e q}^{2}\right)\right]^{\frac{1}{2}}$

In the static fatigue regime, the factor $n_{a}$ is similarly assigned a value of 2, and Eqn. 39 simplifies to:

$$
\vartheta_{n o}=\left[\vartheta_{m i s}^{2}+\vartheta_{m e q}^{2}+0.25\left(\vartheta_{f s}^{2}+\vartheta_{\text {aeq }}^{2}\right)\right]^{\frac{1}{2}}
$$

Then Eqn. 11 is used to obtain $n_{o}$ as:

$$
n_{o}=\exp \left[\begin{array}{l}
\left.z_{o} \sqrt{\ln \left\{\left(1+\vartheta_{s}^{2}\right)\left(1+\vartheta_{n o}^{2}\right)\right.}\right\} \\
+0.5 \ln \left\{\left(1+\vartheta_{s}^{2}\right)\left(1+\vartheta_{n o}^{2}\right)\right\}
\end{array}\right]
$$

\section{A1.2 Miscellaneous Variability}

The miscellaneous variability is considered to consist of variability that is associated with design model formulation, assembly, and installation operations. Simplified models in engineering design have been in practice for over two hundred years. They are generally sufficiently accurate to about $\pm 10 \%$ of reality [34]. The load experienced by equipment in service depends on assembly accuracy and proper installation. The influence of assembly and installation practices on the variability of service load is not easy to assess at the design phase, especially for new products. The usual assumption is that these activities will be done following standard or recommended practices but actual practices may deviate from these. The variability due to design model ( $\left.v_{\text {mod }}\right)$, assembly $\left(v_{\text {ass }}\right)$,, and installation ( $v_{\text {ins }}$ ) activities may be assessed as:

$$
v_{m i s}=\sqrt{v_{\text {mod }}^{2}+v_{\text {ass }}^{2}+v_{\text {ins }}^{2}}
$$

Since engineering models are generally accurate to $\pm 10 \%$, a model coefficient of variation ( $v_{\text {mod }}$ ) of $5 \%$ is suggested. Assuming that the assembly or installation variability is of the same order as that of the design model variability, respectively, then; $v_{\text {ass }}^{2}=v_{\text {ins }}^{2}=v_{\text {mod }}^{2}=0.05$. Hence from Eqn. A5, an estimate of the miscellaneous cov is:

$$
v_{m i s}=\sqrt{0.05^{2}+0.05^{2}+0.05^{2}}=0.0866
$$

The effective value of the miscellaneous variability is therefore taken as $v_{m i s}=0.085(8.5 \%)$.

\section{A1.3 Reliability Estimate}

The reliability estimate based on the unit normal variate is commonly read from Tables given the value of the variate. For use in a spreadsheet, it is more convenient to code a formula. Using data from [13: p. 2.27], a curve fitting study for $1.28 \leq \mathrm{z}<7.0$ for the unit normal curve yielded the following:

$$
\begin{aligned}
& y=0.2006 z^{2}+0.2299 z+0.3818 \\
& R_{z}=1-10^{-y}
\end{aligned}
$$

Equations A7 and A8 may be used to obtain reliability values for known variate $\mathrm{z}$ instead of reading table values. The range of reliability values is wide beginning from $90 \%$ to 11 "nines". Since table values are discrete, interpolation may be needed occasionally. Using equations A7 and A8 avoids interpolation. 